\title{
Use of Herbal Products in Type 2 Diabetes Mellitus Patients
}

\author{
Tuğba Başer, Cenk Aypak and Süleyman Görpelioğlu* \\ Department of Family Medicine, University of Health Sciences, Ankara Dışkapı Yıldırım Beyazıt Training and Research Hospital, Ankara, Turkey
}

\begin{abstract}
Aim: In this study, it was aimed to find out the frequency of utilisation of herbal products in Type 2 Diabetes Mellitus (T2DM) patients. In addition, we aimed to identify the factors that are effective in the use of herbal products.

Methodology: A total of 313 T2DM patients, (210 female (67.1\%) who were referred to Family Medicine Outpatient Clinics of Ankara Dışkapı Yıldırım Beyazıt Training and Research Hospital were included. A pre-prepared questionnaire was applied with face-to-face interview technique in order to determine sociodemographic data, the use of herbal products and the factors affecting the use of herbal products.

Results: The rate of herbal products use at any given period after receiving T2DM diagnosis was found to be $32 \%$. The most preferred products were Cinnamomum zeylanicum, Nigella sativa, Olea europaea and Citrus lemon respectively. A total of $73 \%$ of the patients declared that their physicians never asked about utilisation of herbal products in the past. Herbal usage was found to be more common among patients who have been disease duration $\geq 5$ years ( $\mathrm{p}: 0.003$ ). HbA1c values of women using herbal products were higher than those who did not (p:0.038).

Conclusion: We found that herbal products utilisation is a common practice among T2DM patients along with the long term duration of disease. Most of the physicians are unaware of their patients' herbal use. Therefore, clinicians should evaluate complementary medicine utilisation of their patients at every clinical visit in order to guide the integrative treatment.
\end{abstract}

\section{Introduction}

Type 2 Diabetes Mellitus (T2DM) is emerging as a public health concern because of its increasing prevalence and complications [1]. By 2015 , the number of diabetic individuals in the world is 415 million, but this figure is expected to increase to 642 million by 2040 [2]. In the TURDEP-II study conducted in 2010, it is seen that the frequency of DM in Turkish adult society has reached $13.7 \%$ [3]. The side effects of synthetic medicines, the fact that modern treatment methods are disease-oriented, the inadequacy of modern treatment methods in the treatment of certain diseases and the long and troublesome processes of chronic diseases especially lead to the use of plant products $[4,5]$. Since diabetes is a chronic and progressive disease, patients often seek to find an alternative method that speeds up the treatment process [6]. Studies in Turkey on the use of herbal products in diabetic patients are limited [6-10]. Therefore, the purpose of this study is to find out determine the rate of herbal products use of Type $2 \mathrm{DM}$ patients. In addition, we aimed to determine which products they prefer, and to evaluate the factors that are effective in the use of herbal products.

\section{Materials and Methods}

This descriptive and cross-sectional type research was conducted on 1 March 2017 -1 April 2017 among patients with T2DM who were referred to Ankara Dışkapı Yıldırım Beyazıt Training and Research Hospital Family Medicine Outpatient Clinics. The study was approved by the Local Ethics Committee of Dışkapı Yıldırım Beyazıt Training and Research Hospital. The pre-prepared questionnaire was applied with face-to-face interview technique and body mass index (BMI) was calculated by height-weight measurements. Biochemical values of the patients in the last 6 months were extracted from medical files and recorded. The data obtained from the study were analyzed using Statistical Package for Social Sciences version 24 for Windows. Descriptive statistical methods were used when evaluating study data. Independent sample T-test was used to compare the quantitative data with normal distribution while chi-square test was used to compare categorical data. The results were assessed at a $95 \%$ confidence interval and a significance level of $\mathrm{p}<0.05$.

\section{Results}

A total of 313 T2DM patients, 210 female (67.1\%) and 103 male patients $(32.9 \%)$ were included in the study. The mean age was $63 \pm$ 10.4 years and the mean body mass index (BMI) was $31.6 \pm 5.9 \mathrm{~kg} / \mathrm{m}^{2}$. The socio-demographic and clinical features of study population are presented in table (Table 1).

The proportion of patients using herbal products at any given time after receiving T2DM diagnosis is $32 \%$ (n: 100). A total of 60 patients (19.2\%) were actively using the herbal products during study time. Forty $(12.8 \%)$ of the patients had tried to use herbal products in the past but discontinued. The reasons for discontinuation were not receiving benefit from lowering blood sugar (82.5\%), difficulties

${ }^{\star}$ Correspondence to: Süleyman Görpelioğlu M.D. Prof., Department of Family Medicine, University of Health Sciences, Ankara Dıșkapı Yıldırım Beyazıt Training and Research Hospital, 06110, Ankara, Turkey, Tel: :+903125962033; Email: sgorpelioglu@yahoo.com

Key words: diabetes mellitus, herbal products, alternative medicine

Received: April 02, 2018; Accepted: April 27, 2018; Published: April 30, 2018 
Table 1. Distribution of patients according to sociodemographic data. *Calculated according to the exchange rate dated 9 October 2017 ( 1 USD $=3.6925$ TRY).

\begin{tabular}{|c|c|c|c|}
\hline & & (n) & $(\%)$ \\
\hline \multirow{2}{*}{ Gender } & Female & 210 & 67.1 \\
\hline & Male & 103 & 32.9 \\
\hline \multirow{5}{*}{ Education level } & Uneducated & 59 & 18.8 \\
\hline & Primary school & 196 & 62.6 \\
\hline & Secondary school & 22 & 7 \\
\hline & High school & 22 & 7 \\
\hline & University & 14 & 4.6 \\
\hline \multirow{3}{*}{ Monthly income* } & $405 \$$ & 183 & 58.5 \\
\hline & $405 \$-810 \$$ & 111 & 35.5 \\
\hline & $>810 \$$ & 19 & 6 \\
\hline \multirow{3}{*}{$\begin{array}{l}\text { Duration of } \\
\text { diabetes }\end{array}$} & $<5$ years & 86 & 27.5 \\
\hline & 5-10 years & 56 & 17.9 \\
\hline & $>10$ years & 171 & 54.6 \\
\hline \multirow{3}{*}{ Drug use } & $\mathrm{OAD}$ & 204 & 65.2 \\
\hline & OAD + insulin & 82 & 26.2 \\
\hline & İnsulin & 27 & 8.6 \\
\hline
\end{tabular}

in supply (7.5\%), the doctor's recommendation (7.5\%), and bad taste (2.5\%) respectively. Nearly, all of T2DM patients (98\%) did not change their medical treatment while using herbal products. A total of $73 \%$ of the patients declared that their physicians never asked about utilisation of herbal products in the past. The most preferred herbal product of the patients was Cinnamomum zeylanicum with $58 \%$. Nigella sativa (28\%), Olea europaea (23\%), Citrus lemon (20\%) and Thymus serpyllum (5\%) were preferred. $37 \%$ of patients use more than one biscuit product together. The rate and spectrum of herbal product preferences of the patients are shown in table (Table 2).

A total of $46 \%$ of the patients said they learned about herbal products from their family members and friends, $46 \%$ from television programs, $5 \%$ from the internet and 3\% from the herbalists. Most of the patients (93\%) have stated that they use herbal products to increase the effectiveness of their medical treatment. Patients with T2DM duration $>5$ years have found to be using herbal products more frequently compared to their relatively new diagnosed counterparts $(36.5 \%$ vs 19.7\%; p:0.003). Patients who only use oral antidiabetic drugs (OAD) were found less likely to prefer herbal products $(28.9 \%$ vs $37.6 \%$ $\mathrm{p}: 0.075)$. When $\mathrm{HbAlc}$ values are taken into consideration, the HbAlc values of women who use herbal products were higher than those patients who did not use (8.27 vs 7.65 p:0.038). Comparison of sociodemographic and clinical features of patient groups (herbal product users and not users) are shown in table (Table 3).

\section{Discussion}

Diabetic patients use complementary and alternative medicine (CAM) methods 1.6 times more than non-diabetic patients [11]. It was found that $17 \%-72.8 \%$ of diabetic patients use complementary and alternative medicine [12]. In a study, $88.1 \%$ of diabetic patients using CAM prefer herbal products [13].

Although, studies on frequency of utilization of herbal products by diabetic patients in Turkey are limited, the rate of active herbal product users among T2DM patients was range from $16.6 \%$ to $59.6 \%$ [6-10,13]. This rate can vary among countries. For instance, it was found to be $23.6 \%$ in Australia [14], 29.9\% in Thailand [15] and 50\% in Malaysia [16]. Many factors; such as sampling choice, methodological differences, the region where the study was conducted, the religious and lifestyle believes of the patients, all may effect those rates. In a study conducted with Turkish children with type $1 \mathrm{DM}$, the use of
CAM is increasing in families with high monthly income levels [7]. In our study, the patients with higher income have less use of herbal products. It has been found that the use of CAM increases in diabetic patients over 65 years of age and as education level increases [11]. In our study, primary school graduates and illiterate patients are choosing herbal products more.

In this study, we found that the HbAlc values of women who use herbal products were higher than those who do not use. Poor blood glucose regulation might have increased the need for utilization of herbal products in those patients. In accordance to that finding, patients with longer duration of T2DM were found to be using more frequently herbal products. In addition, $98 \%$ of our patients have declared that they use herbal products to intensify their current medical therapies. This rate is compatible with other studies [6] and those findings support that patients with chronic diseases such as T2DM seek more commonly complementary therapies [17].

In our study, information sources on herbal products were found to be families, friends and television. Although, this finding is compatible with other studies in our country [6-8].

Many of the patients prefer the herbal products because they believe that those products are natural with no harm [18]. Unfortunately, adverse effects may occur depending on the quality of herbal product or its use with other medicines [19].

Therefore, information about those products should be taken from medical professionals which necessitates knowledge about those products [20]. Interestingly, the proportion of patients who do not share the use of TAT with their doctors was $69.2 \%$ [8] and $88 \%$ [6] in studies conducted in our country and 64\% in Thailand [15]. Many factors, such as the level of education and awareness, the frequency of use, and the distance and attitude of the physicians on those methods, have shown to have potential to interfere the patients' preferences on declaration of TAT use with their physicians [18]. In addition, we found that a total of $73 \%$ of the patients declared that their physicians never asked if they utilise any herbal products in the past, which leads to loss of valuable information about the patient.

The most preferred herbal product in study was found to be Cinnamomum zeylanicum. This finding was comparable with previous studies from Turkey [6-8]. Although, we did not have a chance to evaluate the efficiency of herbal products in our study, it was shown that Cinnamomum zeylanicum is effective in glucose regulation in T2DM patients [21]. As herbal product use rates may vary, the preferred herbal product may change among countries. For instance, the most preferred products in Tanzania were Moringa oleifera, Cymbopogon citrullus, Hagenia abyssinica, Aloe vera, Clausena anisata [22]. As discussed above, this shows us that many factors can greatly influence the preferences of patients.

Table 2. Herbal product preferences. $* 37 \%$ of patients use more than one type of herbal product

\begin{tabular}{|c|c|}
\hline Herbal Products & Preference frequency $\% *$ \\
\hline Cinnamomum zeylanicum & 58 \\
\hline Nigella sativa & 28 \\
\hline Olea europaea & 23 \\
\hline Citrus lemon & 20 \\
\hline Tymus serpyllum & 5 \\
\hline Herbal teas & 4 \\
\hline Trigonella foenum-graecum & 2 \\
\hline
\end{tabular}


Table 3. Comparison of socio-demographic and clinical features of patient groups (herbal product users and not users). "Calculated according to the exchange rate dated 9 October 2017 (1 $\mathrm{USD}=3.6925 \mathrm{TRY}$ ).

\begin{tabular}{|c|c|c|c|c|}
\hline & & Users \% / n & Nonusers \% / n & $\mathbf{P}$ \\
\hline \multirow[t]{2}{*}{ Gender } & Female & $32.3 / 68$ & $67.7 / 142$ & 0.46 \\
\hline & Male & $31 / 32$ & $69 / 71$ & \\
\hline Age (Year, Mean \pm SD) & & $59.7 \pm 6.8$ & $62.3 \pm 11.6$ & 0.06 \\
\hline BMI & & $32.2 \pm 6.1$ & $31.7 \pm 6.03$ & 0.63 \\
\hline \multirow[t]{2}{*}{ Education } & Uneducated+Primary school & $29.4 / 75$ & $70.6 / 180$ & 0.033 \\
\hline & $\begin{array}{c}\text { Secondary/High } \\
\text { school+University }\end{array}$ & $43.1 / 25$ & $56.9 / 33$ & \\
\hline \multirow[t]{2}{*}{ Monthly income* } & $405 \$$ & $29.5 / 54$ & $70.5 / 129$ & 0.165 \\
\hline & $>405 \$$ & $35.3 / 46$ & $64.7 / 84$ & \\
\hline \multirow[t]{2}{*}{ Duration of diabetes } & $<5$ years & $19.7 / 17$ & $80.3 / 69$ & 0.003 \\
\hline & $>5$ years & $36.5 / 83$ & $63.5 / 144$ & \\
\hline \multirow[t]{2}{*}{ Drug use } & OAD & $28.9 / 59$ & $71.1 / 145$ & 0.075 \\
\hline & OAD+İnsulin/ İnsulin & $37.6 / 41$ & $62.4 / 68$ & \\
\hline \multirow[t]{2}{*}{ Glucose(mg/dl)(n=231) } & Female & $166.3 \pm 60.8$ & $148.7 \pm 67.3$ & 0.08 \\
\hline & Male & $162.7 \pm 58.9$ & $165.2 \pm 74.3$ & 0.89 \\
\hline \multirow[t]{2}{*}{ HbA1C(n=195) } & Female & $8.27 \pm 1.84$ & $7.65 \pm 1.57$ & 0.038 \\
\hline & Male & $8.26 \pm 1.83$ & $8.08 \pm 1.83$ & 0.76 \\
\hline
\end{tabular}

\section{Conclusion}

Herbal product utilisation is a common complementary method among T2DM patients. Most of the patients did not share the information about herbal products utilisation with their doctor. For this reason, clinicians should keep in mind to evaluate whether their patients use the herbal products or not.

\section{References}

1. CDC (2017) Centre for disease control and prevention. National diabetes sCAMistics report: estimates of diabetes and its burden in the United SCAMes.

2. I.D Atlas (2017) IDF diabetes atlas. International Diabetes Federation, Brussels.

3. Satman I (2013) Twelve-year trends in the prevalence and risk factors of diabetes and prediabetes in Turkish adults. European journal of epidemiology 28: 169-180.

4. Bailey CJ, Day C (1989) Traditional plant medicines as treatments for diabetes. Diabetes Care 12: 553-564. [Crossref]

5. WHO (2017) Organization WH, WHO traditional medicine strategy 2014-2023. WHO Library Cataloguing-in-Publication Data, 2014.

6. Ilhan M, Demir B, YÃksel S, Ãatakl SA, YÄldÄz RS, et al. (2016) The use of complementary medicine in patients with diabetes. North Clin Istanb 3: 34-38. [Crossref]

7. Haliloglu B (2011) Complementary and alternative medicine in children with type 1 diabetes mellitus. JCRPE 3: 139-143.

8. Arýkan D, Sívríkaya SK, Olgun N (2009) Complementary alternative medicine use in children with type 1 diabetes mellitus in Erzurum, Turkey. Journal of clinical nursing 18: 2136-2144.

9. Parildar HR, Serter, Yesilada E (2011) Diabetes mellitus and phytotherapy in Turkey. J Pak Med Assoc 61: 1116-20.

10. Tulunay M (2015) Herbal medicine use among patients with chronic diseases. $J$ Intercult Ethnopharmacol 4: 217-220
11. Egede LE, Ye X, Zheng D, Silverstein MD (2002) The prevalence and pattern of complementary and alternative medicine use in individuals with diabetes. Diabetes Care 25: 324-329. [Crossref]

12. Sheikhrabori A (2016) Complementary and Alternative Medicine Usage and Its Determinant Factors Among Diabetic Patients An Iranian Case. Journal of evidencebased complementary \& alternative medicine 22: 449-454.

13. Ceylan S (2009) Complementary and alternative medicine use among Turkish diabetes patients. Complement Ther Med 17: 78-83.

14. Clifford RM (2003) Prevalence and predictors of complementary medicine usage in diabetes: Fremantle Diabetes Study. Journal of Pharmacy Practice and Research 33: 260-264

15. Sripa S (2005) Usage of and cost of complementary/alternative medicine in diabetic patients. J Med Assoc Thai 88: 1630-1637.

16. Ching SM (2013) Complementary alternative medicine use among patients with type 2 diabetes mellitus in the primary care setting: a cross-sectional study in Malaysia. $B M C$ complementary and alternative medicine 13: 148.

17. Lorenc A, Ilan-Clarke Y, Robinson N, Blair M (2009) How parents choose to use CAM: a systematic review of theoretical models. BMC Complementary and Alternative Medicine 9: 9.

18. Eisenberg DM (1993) Unconventional medicine in the United SCAMes--prevalence, costs, and patterns of use. New England Journal of Medicine 328: 246-252.

19. Bent S (2008) Herbal medicine in the United States: review of efficacy, safety, and regulation. Journal of general internal medicine 23: 854-859.

20. Soner BC, Sahin AS, Sahin TK (2013) A survey of Turkish hospital patients' use of herbal medicine. European Journal of Integrative Medicine 5: 547-552.

21. Khan A, Safdar M, Ali Khan MM, Khattak KN, Anderson RA (2003) Cinnamon improves glucose and lipids of people with type 2 diabetes. Diabetes Care 26: 3215 3218. [Crossref]

22. Lunyera J (2016) Traditional medicine practices among community members with diabetes mellitus in Northern Tanzania: an ethnomedical survey. BMC Complementary and Alternative Medicine 16: 282.

Copyright: (C2018 Bașer T. This is an open-access article distributed under the terms of the Creative Commons Attribution License, which permits unrestricted use, distribution, and reproduction in any medium, provided the original author and source are credited. 